\title{
Onset to hospital admission time and disability in patients with ischemic stroke
}

\author{
Rizaldy Taslim Pinzon', Andre Dharmawan Wijono² \\ ${ }^{1}$ Senior Lecturer, Duta Wacana Christian University School of Medicine Yogyakarta, \\ Indonesia, ${ }^{2}$ Research Assistant, Duta Wacana Christian University School of Medicine \\ Yogyakarta, Indonesia
}

DOI: http://dx.doi.org/10.19106/JMedScieSup0050012018012

\section{ABSTRACT}

The predictive factors of disability in stroke patients are still varied and subject to debate. Lower onset to admission time has been known produces excellent outcomes with significantly lower rates of morbidity and mortality. Previous study about the onset admission time in patients with stroke ischemic in Indonesia is very limited. This was a retrospective cohort study using secondary data from electronic medical record and electronic stroke registry of Bethesda Hospital Yogyakarta Indonesia. A total of 1657 patients with ischemic stroke were admitted between 2015-2017 and 313 patients were included in this study adjusted by inclusion and exclusion criteria. Factors such as age, gender, onset, previous stroke, comorbidities, and complications were assessed. Multiple logistic regression analysis showed onset $>6$ hour (RR: 4.567; 95\% Cl: 2.372-8.792;p: 0.000 ), age (RR: $2.366 ; 95 \% \mathrm{Cl}: 1.357-4.125 ; \mathrm{p}: 0.002)$, and patients with complications (RR: 12.403; 95\% Cl:2.443-62.968;p:0.002) were independently significant increasing the risk of disability in patient with ischemic stroke. Onset to hospital admission time $>6$ hour was significantly increasing disability on ischemic stroke patients. Giving treatment less than 6 hours could save the patient from disability.

Keywords: ischemic stroke - onset to admission time - disability

*corresponding author: dr.andre.dharmawan@gmail.com 